\title{
Moving Characteristics of Coal and RDF in a Swirl-type Precalciner by Numerical Simulation
}

\author{
MEI Shuxia ${ }^{1, a}$, XIE Junlin ${ }^{2, b^{*}}$, CHEN Xiaolin ${ }^{3, c}$, and HE Feng ${ }^{4, d}$ \\ ${ }^{1,3}$ School of Materials Science and Engineering, Wuhan University of Technology, Wuhan 430070, \\ China \\ ${ }^{2,}{ }^{4}$ State Key Laboratory of Silicate Materials for Architectures, Wuhan University of Technology, \\ Wuhan 430070, China

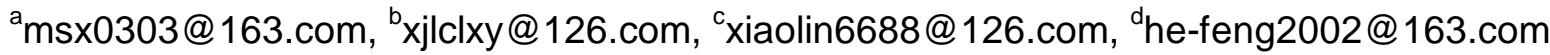

Keywords: precalciner; coal; refuse derived fuel; moving characteristics; numerical simulation.

Abstract. The moving characteristics of coal and RDF in a actual swirl-type precalciner were studied by numerical simulation. The gas phase is expressed with $\mathrm{k}-\varepsilon$ two-equation model and the solid phase is expressed with discrete phase model (DPM). The results show that the coal, carried by the gas flow which rises spirally in the precalciner, moves spirally along the wall of the column section of the precalciner, and the RDF rises spirally around the center axis of the precalciner. Since the RDF gatherers in the upper region, being away from the high concentration region of the coal, the initial combustion of RDF will affect the initial combustion of coal weakly. What we obtain in this study will provide theoretical basis to explore deeply the co-combustion mechanism and interactive influence between pulverized coal and RDF in the precalciner.

\section{Introduction}

Nowadays, more and more attentions are being paid on the cement industry due to its high energy consumption and harmful gas emissions for a long time. With the popularization and promotion of energy conservation and abatement technologies, more strict standards of energy conservation and $\mathrm{NO}_{\mathrm{x}}$ emission against cement industry have been made. Currently, the refuse derived fuel (RDF) combustion technology ${ }^{[1-2]}$ are highly recommended in the cement industry ${ }^{[3-5]}$ because of the advantage on energy saving and harmful emissions reducing. As a kind of alternative fuel of coal, RDF has different physical and chemical characteristics, so there will occur unknown interactive influence during the co-combustion process of coal and RDF. In the precalciner, the coal and RDF go through the furnace carried by gas flow, therefore, it is necessary to study the gas flow form and moving characteristics of particles in the precalciner firstly.

As a very complex large high-temperature reactor, the conventional study methods, by using cold and hot experiments or tests, are almost unworkable to achieve a "viewable" gas flow field and moving characteristics of particles in a precalciner. Today the CFD method has been used widely in precalciner design and optimization ${ }^{[6]}$.

In this paper, aiming an actual swirl-type precalciner, numerical simulation of the moving characteristics of coal and RDF were carried out by gas streamlines, particles trajectory and velocity vector. What we obtain will provide theoretical basis to explore deeply the co-combustion mechanism and interactive influence between pulverized coal and RDF.

\section{Geometrical Model}

Fig. 1 $(a, b)$ presents the structure and mesh of the precalciner. From the bottom, flue gas enters into the precalciner vertically. on the side of the prechamber, tertiary air goes into the precalciner on a tangential direction. The coal inlet locates on the top the prechamber, and the RDF inlet locates at the foot of the column section. In the top section, there is a gooseneck, through which the gas and particles leave the precalciner. 


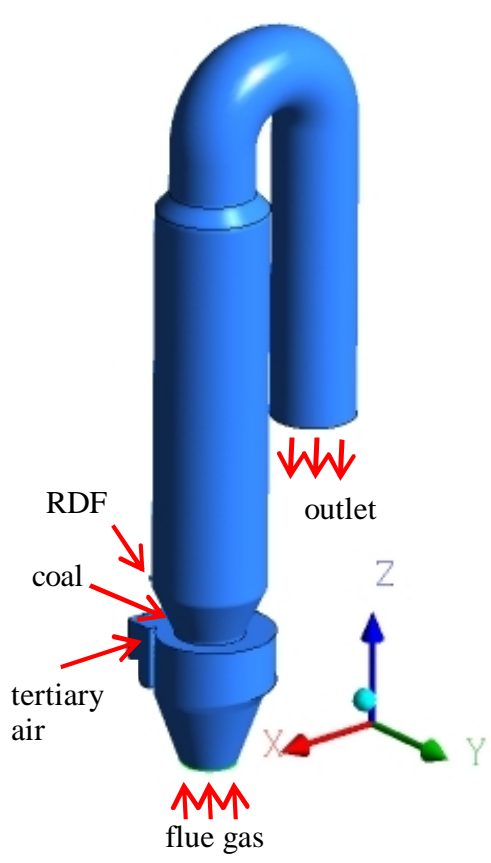

(a) structure

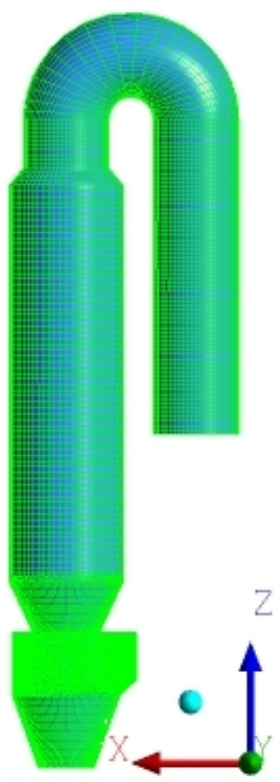

(b) mesh

Fig. 1 Structure and mesh of precalciner

\section{Mathematical Model}

There occur turbulence, gas-solid two phase flow in this research. The sub models are as follows.

\section{A. Turbulence Model}

In Eularian system the fluid phase continuity and momentum equations are solved using the k- $\varepsilon$ model, which is widely used in engineering. The general form of the governing equations for the gas phase is given as follow:

$$
\partial\left(\rho v_{j} \phi\right) / \partial x_{j}=\partial\left[\Gamma_{\phi} \cdot\left(\partial \phi / \partial x_{j}\right)\right] / \partial x_{j}+S_{\phi}
$$

Where $\rho$ is the fluid density, $\varphi$ is the general different variable, $\Gamma_{\varphi}$ is the effective viscosity, $S_{\varphi}$ is the source term.

\section{B. Discrete Phase Model}

The solid phase is solved by the discrete phase model (DPM). The dispersion of particles due to turbulence in the fluid phase is predicted using the stochastic tracking model. For stochastic tracking, the discrete random walk (DRW) model is adopted to account for the generation or dissipation of turbulence in the gaseous phase and the particle trajectory is achieved by integrating the differential equation of forces acting on the particle.

\section{Boundary conditions and numerical scheme}

The numerical procedure for the gas phase flow was based on a well-known volume finite method. The appropriate boundary conditions were as follows. (1) The initial tertiary air velocity was $23 \mathrm{~m} \cdot \mathrm{s}^{-1}$, and the initial flue gas velocity was $17 \mathrm{~m} \cdot \mathrm{s}^{-1}$. (2) The total mass flow of coal was $4.08 \mathrm{~kg} \cdot \mathrm{s}^{-1}$, and $3.61 \mathrm{~kg} \cdot \mathrm{s}^{-1}$ for the RDF. The particle diameters distributed according to the Rosin-Rammler distribution function. (3) At the outlet, the pressure was at an ambient atmosphere. (4) To account for the wall effect in the nearby regions, the wall function was introduced to link velocities in the near-wall region.

The flow field equations with boundary conditions were solved numerically. The process was repeated until convergence was achieved. 


\section{Results and discussion}

Fig. 2 and Fig. 3 presents the gas streamlines from tertiary air inlet and from flue gas inlet, respectively. Fig. 4 and Fig. 5 presents the velocity vector on transverse slice of prechamber and on vertical slice of prechamber, respectively. From Fig. 2 and Fig. 4 we can see that the tertiary air, coming from the side of the prechamber, rotates strongly to the center along the wall, resulting in a strong swirl effect, and then goes up to the column section of the precalciner spirally along the wall, driven by the up-moving flue gas. From Fig. 3 and Fig. 5 we can see that the flue gas, coming from the bottom of the precalciner, goes vertically through the prechamber, and then runs upward spirally around the central axis of the column section of the precalciner, driven by the horizontally rotating tertiary air.

On the whole, there is a spirally rising flow field in the precalciner under the tertiary air and flue gas, which can prolong the residence time and enhance the dispersion degree of coal and RDF.
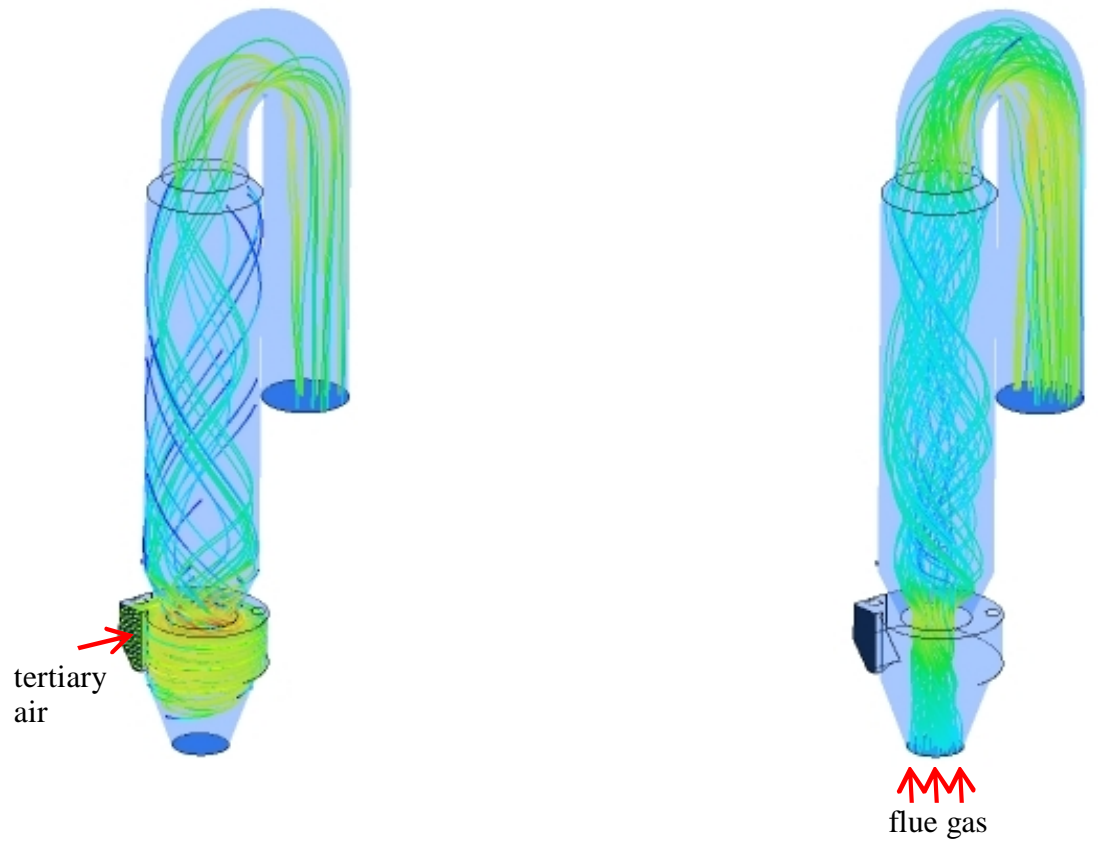

Fig. 2 Gas streamlines from tertiary air inlet

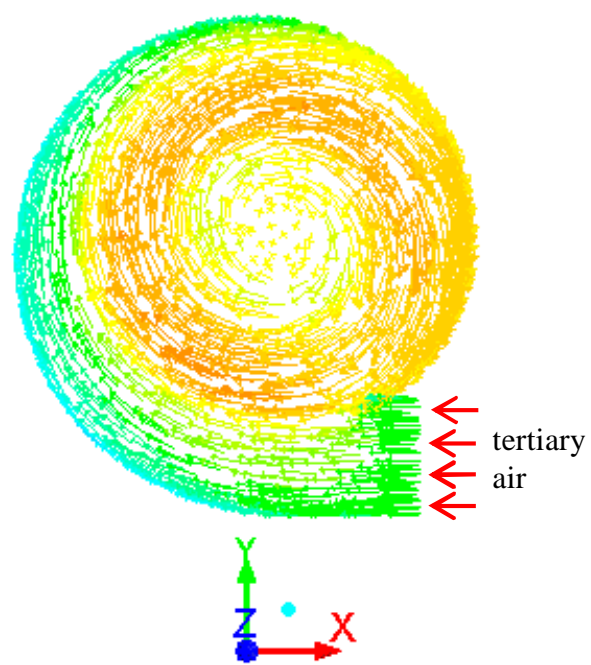

Fig.4 Velocity vector on transverse slice

Fig.3 Gas streamlines from flue gas inlet

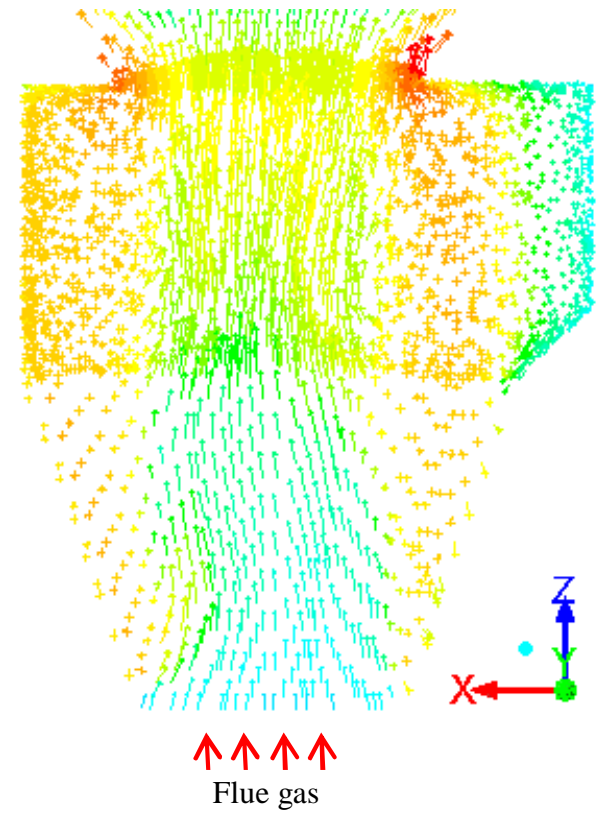

Fig.5 Velocity vector on vertical slice 
Fig. 6 displays the particles trajectory of pulverized coal in the front view and top view. From the front view (Fig.6 (a)) it can be observed that the pulverized coal, coming from the top the prechamber, falls downward into the prechamber in a certain angle at the start, and then turns upward to the column section of the precalciner, rising spirally along the wall (Fig.6 (b)).

Fig. 7 displays the particles trajectory of RDF in the front view and top view. It can be observed that the RDF, coming from the bottom of the column section of the precalciner, goes into the center of the furnace at the start, and then rises spirally around the center axis of the column section.

On the whole, there are "s"-shaped particles trajectory of both pulverized coal and RDF. The trajectory of RDF, by contrast, has a shorter pitch, being beneficial to prolong the residence time of RDF.

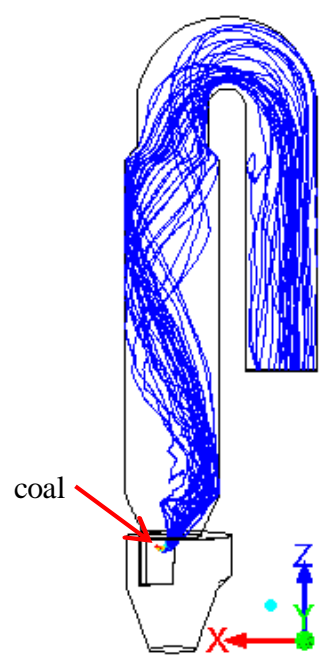

(a) front view

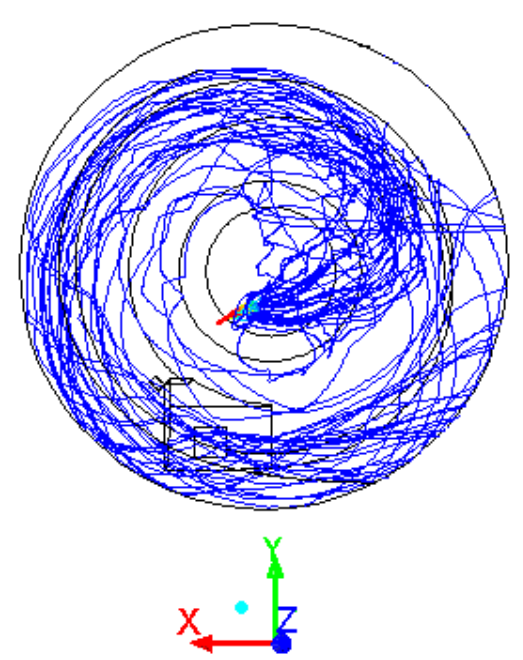

(b) top view

Fig.6 Particles trajectory of coal

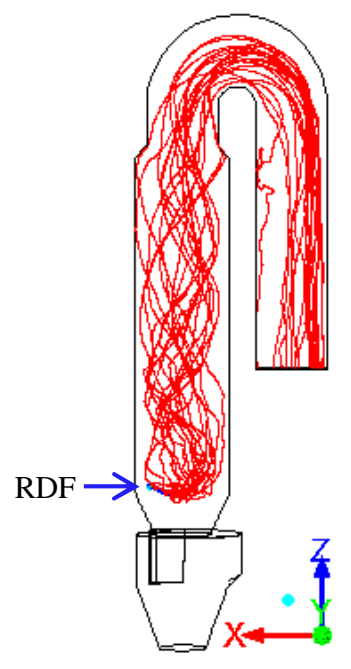

(a) front view

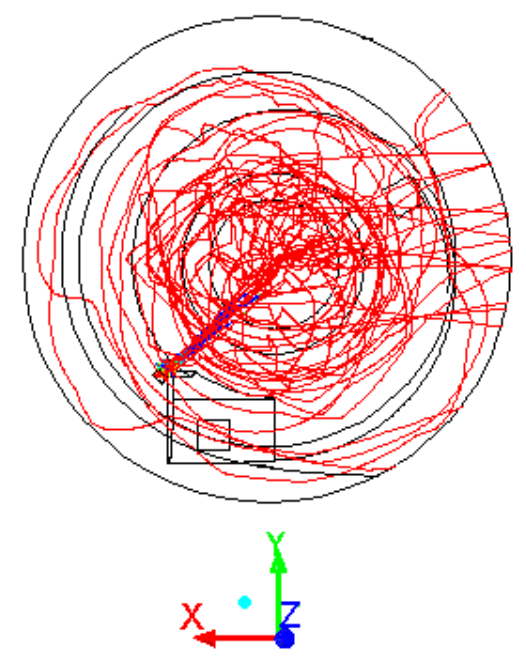

(b) top view

Fig.7 Particles trajectory of RDF

Fig. 8 shows the average concentration of particles along Z direction. Combining Fig.6 (a) and Fig.8, we can know that the pulverized coal gatherers in the prechamber (in the range of $Z_{1} \sim Z_{3}$ ) at the start with a high concentration at the height of $Z_{2}$, which is near the top the prechamber, where the coal will begin to catch fire. Combining Fig.7 (a) and Fig.8, we can know that the RDF gatherers in the cone section and the bottom of the column section of the precalciner (in the range of $Z_{4} \sim Z_{6}$ ) at the start with a high concentration at the height of $\mathrm{Z}_{5}$, where the $\mathrm{RDF}$ will begin to catch fire. 
It can be seen that there is not overlap region of high concentration particles between the coal and the RDF, indicating that the initial combustion of RDF will affect the coal initial combustion weakly since the RDF gatherers in the upper region. On the contrary, the coal combustion will bring unknown effect to the RDF combustion since the coal gatherers in the lower region.

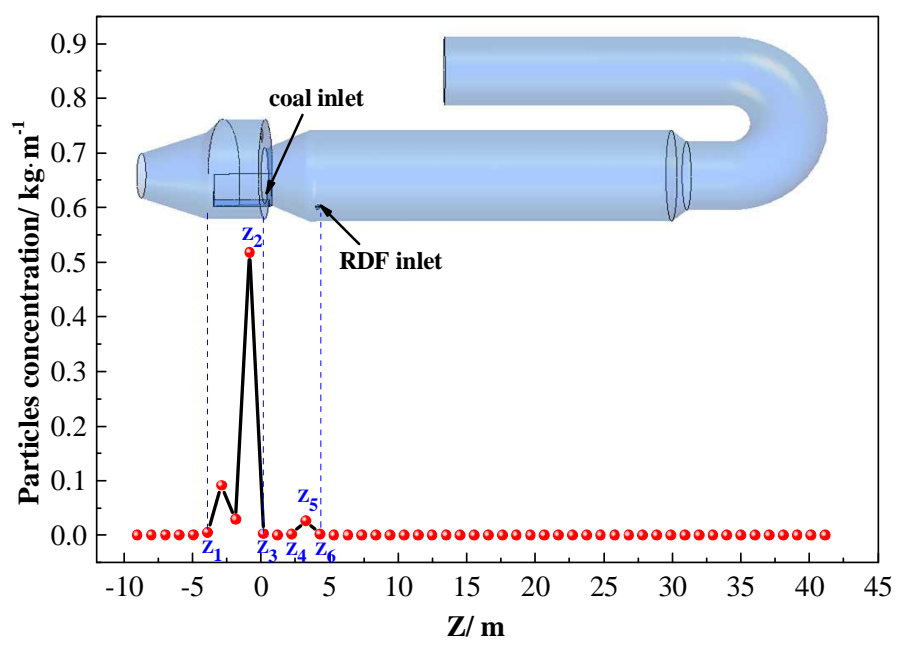

Fig.8 Average concentration of particles along $\mathrm{Z}$ direction

\section{Conclusions}

In this paper, the numerical simulation of moving characteristics of coal and RDF in a swirl-type precalciner were carried out. The simulation results show that there is a spirally rising gas flow field in the precalciner when the vertical up-moving flue gas from the bottom meets the horizontal revolving tertiary air. Carried by the gas flow, the coal rises spirally along the wall of the column section of the precalciner, and the RDF rises spirally around the center axis of the precalciner. the initial combustion of RDF will affect the initial combustion of coal weakly since the RDF gatherers in the upper region, being away from the high concentration region of the coal.

\section{Acknowledgements}

This work was financially supported by the National Natural Science Foundation of China (51502221).

\section{References}

[1] Roman Weber, Tomasz Kupka , Krzysztof Zajac . Jet flames of a refuse derived fuel [J] . Combustion and Flame , 2009 , 156(4) : 922-927.

[2] Akio Yasuhara, Yuko Amano , Takayuki Shibamoto . Investigation of the self-heating and spontaneous ignition of refuse-derived fuel(RDF) during storage[J] . Waste Management , 2010 , 30(7) : 1161-1164.

[3] Mustafa Kara, Esin Günay, Yasemin Tabak, et al. Development of Refuse Derived Fuel for Cement Factories in Turkey [ J ] .Combustion Science and Technology,2011,183 ( 3 ) :203-219.

[4] Mustafa Kara . Environmental and economic advantages associated with the use of RDF in cement kilns[J] . Resources,Conservation and Recycling , 2012 , 68 : 21-28. 
[5] Aranda Usón, AnaM. López-Sabirón, Germán Ferreira, et al. Uses of alternative fuels and raw materials in the cement industry as sustainable waste management options [ J ] . Renewable and Sustainable Energy Reviews, 2013;23:242-260.

[6] HU Zhijuan, LU Jidong, Huang Lai, et al. Numerical simulation study on gas-particles two-phase flow in pre-calciner [J]. Commun Nonlinear Sci Numer Simul, 2006, 11(3): 440-451 